\title{
How to talk with dying patients and their families after disasters and humanitarian crises: a review of available tools and guides for disaster responders
}

\author{
B. R. Daubman ${ }^{1}$, H. Cranmer², L. Black ${ }^{3}$ and A. Goodman ${ }^{4 *}$
}

\begin{abstract}
In responding to those affected by sudden onset disasters and chronic humanitarian crises, disaster responders and humanitarian aid workers will face the challenge of caring for dying patients. While medical intervention may be severely limited or constrained, bearing witness by listening and being able to compassionately communicate with such victims and their families is an important skill. This review examines the current literature on communication training and palliative care-skills for disaster workers and offers a menu of communication tools including guidelines developed for administering palliative care in non-disaster settings that can be used by both disaster responders and humanitarian aid workers.
\end{abstract}

Keywords: Palliative care in disasters, Delivering bad news, Disaster training, SPIKES protocol, Psychological first aid, Serious illness conversation

\section{Introduction}

Delivering bad news is a challenge for healthcare providers in tertiary care settings despite the ample resources available; these include consultant expertise, medications, intensive care units, and nursing care (Fallowfield and Jenkins 2004). In contrast, although palliative care is considered a standard of essential healthcare delivery in crises (The Sphere Handbook 2018), such as after a sudden onset disaster, such as an earthquake, first responders from the incoming disaster teams and aid workers have few tools and little training to help care for dying or catastrophically injured victims (Goodman and Black 2018; Nouvet et al. 2018). It is important to note that the local community provides crucial initial interventions of search and rescue, aid, and medical care (Binder and Baker 2017). These community responders will be the first to face the difficult job of caring for dying family members, friends, and neighbors. Palliative care is

\footnotetext{
* Correspondence: AGOODMAN@mgh.harvard.edu

${ }^{4} \mathrm{MGH}$ Global Health, Department of Obstetrics and Gynecology,

Massachusetts General Hospital, Boston, USA

Full list of author information is available at the end of the article
}

defined as specialized medical care for those living with serious illness that is focused on relief of symptoms, with a goal of improving quality of life for the patient and family (CAPC Center to Advance Palliative Care 2019). How do we as responders prioritize palliative and end-of-life care with so little time and limited resources? The challenges of end-of-life care have been described in Ebola treatment centers (Dhillon et al. 2015) and other complex humanitarian crises (Marston et al. 2015; Rosoff 2010). This review describes the settings, challenges, resources, and tools to allow responders to best communicate with and comfort both families and seriously injured victims who are triaged to the expectant category either because of nonsurvivable injuries or because of life-limiting chronic illness in austere settings where sufficient medical care is unavailable.

\section{Methods}

A search for peer-reviewed papers from 1980 to 2019 via the Ovid MEDLINE database, followed by a PubMed search to pick up more recent papers not currently indexed, was used. In addition, references for included 
papers were crosschecked to ensure that all relevant literature was identified and included. A combination of terms describing palliative care in disasters, delivering bad news, and disaster training was used in the search. Additionally, an Internet search was done to identify current established disaster training and humanitarian training programs and the curriculums they offered to disaster responders and humanitarian aid workers. A total of 423 papers were reviewed.

For inclusion, papers must have described communication skills tools or the needs of the health professionals for such training. Knowledge and behavioral and attitudinal learning outcomes were included. Papers were excluded if not available in English or did not include an adequate description of the communication tool intervention. Any study design was eligible for review. A final 96 references of papers and websites were included in this review.

\section{The disaster setting}

Sudden onset disasters include catastrophic natural events such as earthquakes, floods, hurricanes; no-notice events like terrorist mass casualty events; emerging infectious diseases such as outbreaks; and humanitarian crises such as the displacement of large groups of people due to violent conflicts that overwhelm the local resources and infrastructures (WHO 2018a). Additionally, large displacements due to famine, drought, and economic collapse have led to chronic and escalating humanitarian crises (Abubakar et al. 2019). People who live in these challenging settings, as well as those populations in resource-limited environments such as low- and middle-income countries (LMICs), which have limited medical and social service infrastructures at baseline, are all disproportionately impacted by disasters (UNISDR 2015). There are now more people displaced than at any other recorded time and are thus more likely to have increased morbidity and mortality (UNHCR 2018). During the initial phases of such disasters, the environment is chaotic and potentially lawless and dangerous, with few resources for the victims (UNHCR 2019). In many LMICs, pre-existing laws protecting women, children, and other vulnerable populations are limited and risks for injury and violence are exacerbated by sudden onset disasters and escalating complex humanitarian crises (Morgan Banks et al. 2017). Food, shelter, medical personnel, and supplies may be scarce, and the ability to provide the normal standard of medical care is compromised. Analysis of medical needs in the initial post-disaster period documents a preponderance of disaster-related injuries in the first 2 weeks before shifting back to more routine population health needs (Cartwright et al. 2017). In the immediate post-disaster setting, there is also an exacerbation of pre-existing conditions and patients who are chronically ill compete for limited medical resources with acutely injured victims (Goodman and Black 2015).

In the immediate aftermath of a disaster, priorities are categorized, and for the population we are examining, personal shelter and safety are immediate needs, especially for those at risk for death or serious illness (UNHCR 2019; Zhao et al. 2017). In these settings, victims needing palliative care who are catastrophically injured or dying often are not afforded ideal symptom management in the setting of privacy, dignity, and safety from further hazards or threats (Nouvet et al. 2018). Providers, to remain healthy and effective in the disaster setting, need training in order to identify and treat this particular population. This is especially pronounced with regard to cultural competency and communication, in addition to the skillsets needed for clinical work. In addition, ethical issues are pertinent to all aspects of disaster response and include five domains: triage and allocation, ethical concerns of patients and families, provider responsibilities, conduct of research, and international concerns (Biddison et al. 2014).

\section{Triage and resource allocation}

The fundamental treatment decisions in a disaster are based on triage category, which is applied at the point of disaster and can be re-assigned when transported to a higher level treatment area (Barilan et al. 2014; Caro et al. 2011). Color-coded or numbered categories indicate to providers the degree of injury and the likely resources that are needed (Table 1). Disaster triage includes "expectant management," that is, it is anticipated that the outcome for those in this category is death (Burkle 2018). Injuries vary from the lightly wounded, green color code, who can be treated and discharged, to those who must be stabilized and transported to a higher level facility, red color code, and also to those placed in the blue color code or expectant category (Alpert and Jaffe 2018; WHO/ICRC 2017). Another category of patients not listed in classic triage are those who are not injured but present for treatment to first responder field hospitals due to a lack of other resources. For instance, this group needs reproductive healthcare such as obstetrical management or has decompensated congestive heart failure, hypertensive emergency, and chronic renal failure on dialysis (Lempert and Kopp 2013). Patients are categorized as expectant when survival is not likely given the care that is available.

Standard triage categorization makes no mention of palliative care and implies that expectant patients require even less attention than those in the minimal injury (green color code) category (Wilkinson 2012; Bogucki and Jubanyik 2009). In 2018, the World Health 
Table 1 Recommended triage categories in disaster or crisis

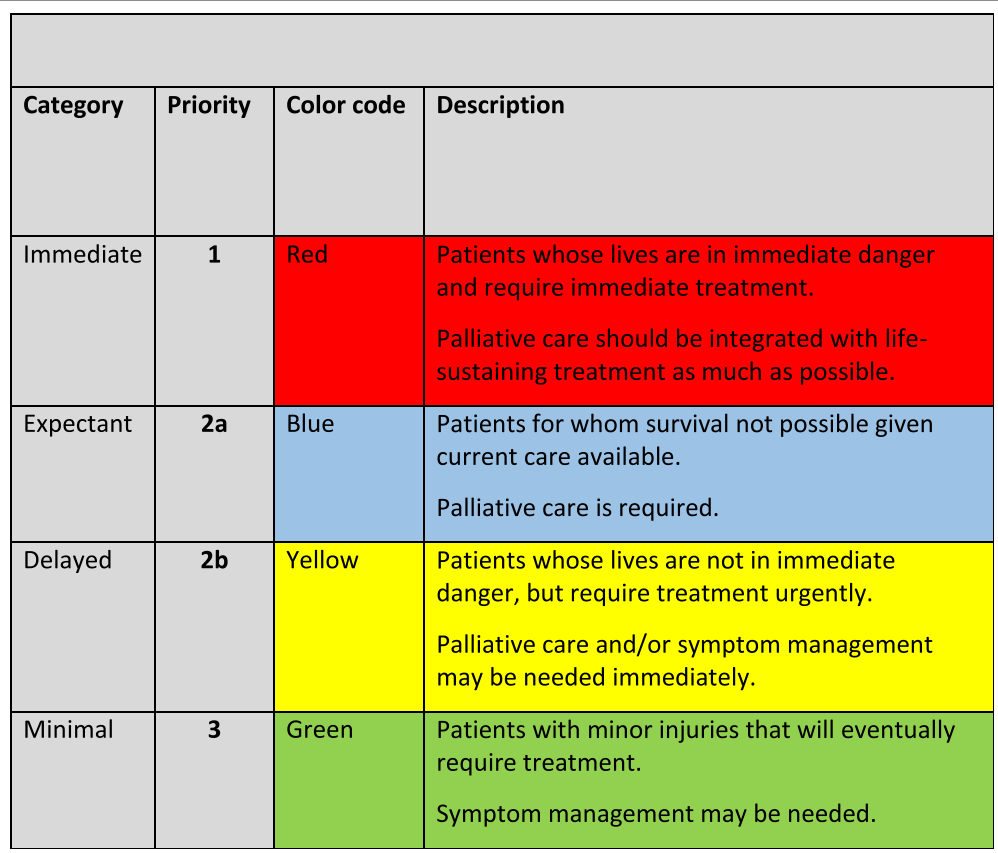

(Source: Adapted from WHO et al. 2018)

Organization (WHO) recommended a revision of the standard triage categorization in humanitarian emergencies and crises so that expectant patients (blue color code) are placed in category $2 \mathrm{a}$ and it is noted that palliative care is required (Table 1) (WHO 2018b). The Sphere Handbook has added a palliative care standard (The Sphere Handbook 2018). This states that people should have access to palliative and end-of-life care that relieves pain and suffering; maximizes the comfort, dignity, and quality of life of patients; and provides support for family members. Palliative care may also free up resources to improve survival of others (Matzo et al. 2009; Fowler-Kerry and Cunningham 2010) and may also mitigate political tensions and promote understanding (Cherny 2007). Palliative care for expectant patients includes end-of-life symptom management as well as communication skills such as delivering bad news (Smith and Aloudat 2017; Downar et al. 2010).

\section{Current disaster training}

Current disaster training and skillset development for responders occur before deployment, on site during work in a disaster setting, and through after-action briefings, and are meant for clinical and non-clinical staff, including those involved in logistics. During mass casualty events, administration, operations, and organization of the responders' work site are vital (Dudley 2013). The National Preparedness Directorate of the Department of Homeland Security (DHS) established the Homeland Security Exercise and Evaluation Program (HSEEP) in the USA (DHS. The U.S. Department of Homeland Security 2013). The HSEEP program provides resources and tools for jurisdictions and organizations to evaluate their disaster plans, which include tabletop, and field exercises. This mandatory training focuses on organizational and infrastructure issues for disaster response and does not address the care of individual victims of disasters. Hospital disaster planning and training is another mechanism for the development of a response plan (Grock et al. 2017). Hospital personnel training in resource-limited countries such as Pakistan and Haiti has been advocated to develop a response capacity checklist and increase personnel training (Smith et al. 2010). These hospital disaster drills focus on incident command systems, managing surge capacity, and triage with little training in patient-directed communication.

Other pre-deployment training ranges from online modules and classroom seminars to complex "on-theground" simulations (Smith et al. 2012; Sabri and Qayyum 2006; Harvard Humanitarian Initiative (HHI) 2018a; Harvard Humanitarian Initiative (HHI) 2018b; Humanitarian 2018). The main goals of these trainings include safety and security, specific medical and survival skillsets, and team and leadership building. Importantly, training also focuses on hospital capacity, triage, and resource allocation (Smith et al. 2010; Kushner et al. 2007). In a survey of responders to the 2015 Nepali earthquake, responders working with experienced organizations received general training in humanitarian principles, while those joining ad hoc groups did not receive pre-deployment training 
(Dunin-Bell 2018). Little to no time is spent on palliative care training (Smith and Aloudat 2017). While many simulations include training in negotiations with hostile host populations, these role-plays have not included delivering bad news. A nursing education curriculum has been developed on the delivery of culturally competent care to vulnerable patients and communities (including the terminally ill) during the disaster cycle as part of pre-departure and in-field training (Danna et al. 2015). On-the-job training with triage in mass casualty care has been analyzed for military operations but does not include support with difficult communications (De Jong et al. 2010). On-site training with peer-to-peer education has been instituted by aid agencies (Asgary and Jacobsen 2013). In addition, training of community volunteers has been associated with increased resilience during and after a catastrophe (Thormar et al. 2013). While the curriculum for on-site training includes didactic sessions and clinical and public health topics, there is limited skill building in communication and delivery of bad news. A training model in the non-disaster setting used simulation-based training to improve skills for end-of-life care (Brezis et al. 2017). In the workshop setting, role-play also effectively improved listening and communication skills (Jacobsen et al. 2017). Simulated patients are another tool used to train students and physicians in how to break bad news in a non-disaster setting (Vail et al. 2011).

\section{Cultural competency training}

Cultural barriers to providing good communication and health care in non-disaster settings include organizational barriers that consist of structural policies, procedures, and delivery systems that may not appropriately serve a population in the host community or country (Betancourt et al. 2003). According to the National Institutes of Health, culture is a complex mix of geographic, social, ethnic, and religious mores (National Institutes of Health (NIH) 2017). Culture includes societally accepted beliefs and behaviors (IFRC 2014). Cultural respect is important as part of comforting victims and also as part of a disaster team's diplomatic mission in a foreign land (Kelman 2012). Pre-deployment training is necessary for cultural competency (Betancourt et al. 2003).

"Cultural competency" addresses the importance of culture, assessment of cross-cultural relations, vigilance toward the dynamics that result from cultural differences, expansion of cultural knowledge, and adaptation of services to meet culturally unique needs (Rollins and Hauck 2015). Awareness of health beliefs and behaviors is a crucial aspect of cultural competency (Lavizzo-Mourey and Mackenzie 1996). In a survey on knowledge and needs for cultural competency in disasters, $62 \%$ and $20 \%$ of nurses and $83 \%$ and $6 \%$ of nurse executives felt that training was either needed or a high priority respectively (Danna et al. 2015). Danna et al. developed a nursing education model, "Cornerstone of cultural competency during the disaster cycle $\left(C^{3} \mathrm{DC}\right)$," that incorporated three domains of competence in nursing: theory and scientific methods, skillful practice, and professional identity and agency. Table 2 summarizes the $\mathrm{C}^{3} \mathrm{DC}$ and emphasizes the importance of knowledge of the disaster cycle from the pre-disaster planning, to response, and finally to recovery work. Each phase of a disaster requires a particular knowledge and skillset in talking with the affected communities and delivering bad news.

The psychological impact of disasters on the population is associated with pre-disaster factors (experience/ training, income, life events/health, job satisfaction), peri-disaster factors (exposure, peri-traumatic experiences, perceptions of safety, injury), social factors (organizational and social support), and post-disaster factors (impact on life) (Brooks et al. 2017).

Language barriers can prevent informed information interchange. A negative consequence of poor communication skills during a crisis is the development of mistrust and potential violence against responders (Matzo et al. 2009). Table 3 summarizes issues of cultural competency important to consider when working in a foreign country.

\section{Communicating bad news}

One of the core skills of palliative care is competent communication, including clear delivery of information about prognosis and goals of care. "Bad news" is any information that alters a patient or victim's expectations of their future (Barclay et al. 2007; Ptacek and McIntosh 2009). In a disaster setting, communication of bad news to a victim or family member involves providing information about the significance of injuries, the outcomes of the injuries, and the potential for survival. Communicating bad news is relevant to other categories of triaged patients besides the expectant, for example, an injured patient who will require a significant body alteration such as an amputation or a colostomy to survive. Patients who are so severely injured as to be placed in the expectant category are usually too ill to communicate, and responders must communicate with a family member if present (Powell 2010).

Several standard tools exist to provide clinicians with a structure for delivering bad news. We are not aware of any tools that have been adapted for delivery of bad news in the disaster setting. Many of these tools have been analyzed in the tertiary, non-disaster setting and through questionnaires have identified the need for improved training and skills (Monden et al. 2016). None of these tools have been validated. However, a review of different teaching strategies for delivering bad news 
Table $2 C^{3} D C$ model for disaster education

\begin{tabular}{|c|c|c|}
\hline $\begin{array}{l}\text { Phase of } \\
\text { disaster }\end{array}$ & Education and training & Implications for palliative care \\
\hline $\begin{array}{l}\text { Prevention and } \\
\text { mitigation }\end{array}$ & $\begin{array}{l}\text { Risk reduction, disease prevention, health promotion, } \\
\text { policy development and planning, mitigation }\end{array}$ & $\begin{array}{l}\text { Understand the incidence and prevalence of life } \\
\text { limiting diseases in the community }\end{array}$ \\
\hline Preparedness & $\begin{array}{l}\text { Ethical practice, legal practice and accountability, } \\
\text { communication and information sharing, education } \\
\text { and preparedness }\end{array}$ & $\begin{array}{l}\text { Understand the existing laws and protections for } \\
\text { vulnerable populations; educate populations about } \\
\text { healthcare proxy designation }\end{array}$ \\
\hline Response & $\begin{array}{l}\text { Care of the community, care of individuals and families, } \\
\text { psychological care, care of vulnerable populations }\end{array}$ & $\begin{array}{l}\text { Training responders in communication skills } \\
\text { and triage }\end{array}$ \\
\hline Recovery & $\begin{array}{l}\text { Long-term individual, family, and community recovery, } \\
\text { building resilience }\end{array}$ & Bereavement counseling \\
\hline
\end{tabular}

(Source: adapted from Danna et al. 2015)

identified simulation and Objective Structured Clinical Examination (OSCE) as the best approach for trainees (Lamba et al. 2016). The new SPHERE chapter identifies palliative care as an important health intervention but does not address communication skills and delivery of bad news in particular (The Sphere Handbook 2018).

The "SPIKES" model (Table 4) was initially developed in reference to cancer patients but is applicable to a wide variety of clinical situations. This model guides the clinician through a 6-step communication process with patients (Baile et al. 2000). Step one, the Set Up, involves the clinician's preparation for the discussion. Even in an austere environment, it is crucial to strategize about ways to arrange for a more private environment, ensure the right family/community members are present, and involve an interpreter if needed.

Step 2 involves assessing Perception, which allows the clinician to ascertain the patient/family's illness understanding. This prepares the clinician to be able to fill in informational gaps and understand how the patient/family may respond when information is delivered.
Step 3 involves obtaining the patient/family's Invitation. This includes listening and speaking with cultural humility and assessing through a cultural guide, interpreter, or family members how much a patient or family wants to know about the clinical situation.

Notably, the halfway point of the SPIKES acronym is reached before the serious news is actually delivered, running counter to many clinicians' natural inclinations, particularly when pressed for time or feeling uncomfortable with the news.

In step 4, Knowledge involves delivering the bad news in concise, simple language. Warning the patient that bad news is coming may lessen the shock that can follow the disclosure of bad news (Maynard 1996) and may facilitate information processing (Greisinger et al. 1997). It is important to provide information that is at a level that the patient can understand. Avoid the use of medical jargon. When speaking through an interpreter, responders may need to have a conversation with the interpreter before meeting the patient to explain the situation and the need to be sensitive.

Table 3 Components of cultural competency

\begin{tabular}{|c|c|c|}
\hline Components & Considerations & Example \\
\hline Dress & $\begin{array}{l}\text { 1. Respectful clothing appropriate to region } \\
\text { 2. Do host people need certain clothing to maintain } \\
\text { their dignity? }\end{array}$ & $\begin{array}{l}\text { 1. Tank tops, short skirts inappropriate in Muslim country } \\
\text { 2. Cover people with torn or absent clothing with a blanket }\end{array}$ \\
\hline Language & $\begin{array}{l}\text { 1. What is the language? } \\
\text { 2. How to greet people? }\end{array}$ & Learn words for hello, how are you, thank you, good bye \\
\hline $\begin{array}{l}\text { Gender, age, } \\
\text { power }\end{array}$ & $\begin{array}{l}\text { 1. Can male responders treat and care for women? } \\
\text { 2. Who is the community leader? } \\
\text { 3. Who is the decision maker in the family? }\end{array}$ & $\begin{array}{l}\text { 1. Be aware that in some cultures, community leaders may } \\
\text { traditionally be involved in medical decision-making } \\
\text { 2. Identify patient preferences regarding how medical information } \\
\text { is shared }\end{array}$ \\
\hline $\begin{array}{l}\text { Touching and } \\
\text { behavior }\end{array}$ & $\begin{array}{l}\text { 1. What are the usual customs for touching? } \\
\text { 2. Is it ok to hold someone's hand? } \\
\text { 3. What are special considerations for interaction } \\
\text { with women, children, elderly? }\end{array}$ & $\begin{array}{l}\text { 1. In some cultures, "thumbs up" is a rude gesture } \\
\text { 2. Touching someone's head or face is rude in South Asia } \\
\text { 3. Showing the soles of your feet is rude in the Middle East }\end{array}$ \\
\hline $\begin{array}{l}\text { Beliefs and } \\
\text { religion }\end{array}$ & $\begin{array}{l}\text { 1. Who are the different ethnic and religious groups } \\
\text { of the region? } \\
\text { 2. What are the beliefs and practices that are important? } \\
\text { 3. How might they understand or explain what has happened? }\end{array}$ & $\begin{array}{l}\text { 1. Ask if the patient would want a religious leader present at } \\
\text { end-of-life } \\
\text { 2. Ask about patient/family's beliefs about treatment of the body } \\
\text { (viewing, handling, burial) after death (WHO et al. 2018) }\end{array}$ \\
\hline
\end{tabular}


Table 4 SPIKES tool in the disaster setting

\begin{tabular}{|c|c|c|c|}
\hline & Acronym & Description of steps & Example phrasing \\
\hline $\mathrm{S}$ & Setting up the interview & $\begin{array}{l}\text {--Arrange for some privacy } \\
\text {--Involve family members (if desired) } \\
\text {--Sit down } \\
\text {--Make connection with the patient } \\
\text {--Manage time constraints and interruptions }\end{array}$ & \\
\hline$P$ & $\begin{array}{l}\text { Assessing the patient's } \\
\text { perception }\end{array}$ & $\begin{array}{l}\text {--Ask, tell, ask (before discussing medical findings, use } \\
\text { open-ended questions to understand the patient/family's } \\
\text { perception of their situation) } \\
\text {--Allows clinician to correct misinformation and tailor the } \\
\text { bad news to where the patient/family's understanding is }\end{array}$ & $--^{-" W h a t ~ i s ~ y o u r ~ s e n s e ~ o f ~ h o w ~ y o u r ~ m o t h e r ~ i s ~ d o i n g ? " ~}$ \\
\hline । & $\begin{array}{l}\text { Obtaining the patient's } \\
\text { invitation }\end{array}$ & $\begin{array}{l}\text {--Ask permission before giving the news } \\
\text {--Assess through a cultural guide /interpreter/ family } \\
\text { members how much a patient wants to know }\end{array}$ & $\begin{array}{l}\text {--"Would it be okay if I talk to you about what's happened } \\
\text { with your mother's injuries?" } \\
\text {-- "Is there anyone else who should be here for this } \\
\text { conversation?" }\end{array}$ \\
\hline K & $\begin{array}{l}\text { Giving knowledge and } \\
\text { information }\end{array}$ & $\begin{array}{l}\text {--Give a warning shot } \\
\text {--Give key information in concise, simple language } \\
\text {-Stop talking }\end{array}$ & $\begin{array}{l}-- \text {-"Unfortunately I have some difficult news to tell you." } \\
-- \text { "Because of the damage to your leg, it will require } \\
\text { amputation above the knee." } \\
-- \text { (Pause) }\end{array}$ \\
\hline E & $\begin{array}{l}\text { Addressing the patient's } \\
\text { emotion with empathic } \\
\text { responses }\end{array}$ & $\begin{array}{l}\text {--Allow for silence } \\
\text {--Name the emotion } \\
\text {--Align with the patient }\end{array}$ & $\begin{array}{l}--" \text { You seem devastated to hear this." } \\
--{ }^{-1} \text { really wish we had a treatment to save your father's life." }\end{array}$ \\
\hline S & Strategy and summary & $\begin{array}{l}\text {--Map out what is most important to the patient } \\
\text {--Make a recommendation }\end{array}$ & $\begin{array}{l}--{ }^{-\prime G i v e n ~ t h i s ~ h a r d ~ s i t u a t i o n, ~ w h a t ' s ~ m o s t ~ i m p o r t a n t ~ r i g h t ~} \\
\text { now?" } \\
--{ }^{\prime \prime} \text { In light of what you told me about your mother not } \\
\text { wanting to suffer, I recommend that we give her } \\
\text { medication to treat her pain and focus on her comfort." }\end{array}$ \\
\hline
\end{tabular}

(Source: adapted from Baile et al. 2000)

Table 5 Serious IIIness Conversation Guide for the disaster medicine setting

\begin{tabular}{|c|c|c|}
\hline Steps & Description of steps & Example phrasing \\
\hline $\begin{array}{l}\text { Setting up the } \\
\text { conversation }\end{array}$ & $\begin{array}{l}\text {--Introduce purpose of the conversation } \\
\text {--Ask permission }\end{array}$ & $\begin{array}{l}--^{-\prime \prime \prime d ~ l i k e ~ t o ~ t a l k ~ a b o u t ~ w h a t ' s ~ b e e n ~ h a p p e n i n g ~ w i t h ~ y o u r ~ m o t h e r ' s ~ h e a l t h ~} \\
\text { situation. Would that be okay?" }\end{array}$ \\
\hline $\begin{array}{l}\text { Assessing the } \\
\text { prognostic } \\
\text { awareness }\end{array}$ & $\begin{array}{l}\text {--Elicit patient/family illness understanding } \\
\text {--Explore hopes and worries }\end{array}$ & 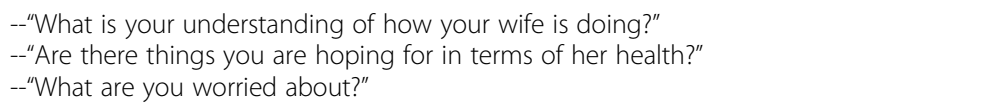 \\
\hline Share worry & --Disclose condition/prognosis & $\begin{array}{l}--{ }^{-\prime B e c a u s e} \text { of the injuries your father experienced in the earthquake, I am worried } \\
\text { that time is quite short for him." } \\
\text {--"I hear you are hoping that we'll be able to treat your son's cholera, and I'm worried } \\
\text { that even with the medicine we are giving him, he may die from this." }\end{array}$ \\
\hline Align & $\begin{array}{l}\text {--Align with patient/family through: } \\
- \text {-I wish" statements } \\
\text {-Naming emotion } \\
\text { - Exploring emotion }\end{array}$ & $\begin{array}{l}--" \text { I wish we had a treatment that could fix your sister's injuries." } \\
--{ }^{\prime \prime} \text { It sounds like you are shocked to hear this." } \\
-- \text { "This must be so difficult to hear." } \\
---^{-C} \text { Can you tell me more?" }\end{array}$ \\
\hline $\begin{array}{l}\text { Explore what } \\
\text { is important }\end{array}$ & $\begin{array}{l}\text {--Explore the patients' fears, worries, goals, } \\
\text { sources of strength, and family support. }\end{array}$ & $\begin{array}{l}-- \text { "You mentioned that your mother's faith is a source of strength. Are there rituals it } \\
\text { would be important to perform at this time?" } \\
\text {--"Often patients have worries about dying in pain. Do you think your husband may } \\
\text { worry about that?" }\end{array}$ \\
\hline $\begin{array}{l}\text { Close the } \\
\text { conversation }\end{array}$ & $\begin{array}{l}\text {--Summarize the news given } \\
\text {--Make a recommendation } \\
\text {--Affirm commitment to the patient and } \\
\text { family }\end{array}$ & 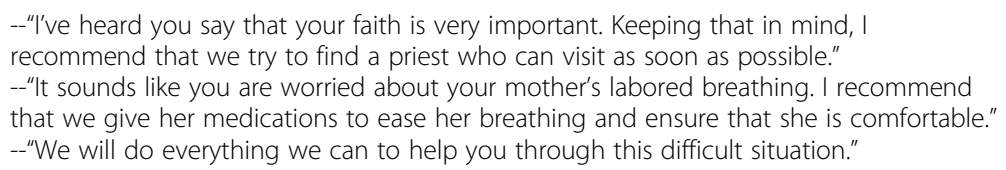 \\
\hline
\end{tabular}


Information should be provided in small chunks with frequent check-ins to make sure the patient and/or their family understands. Pausing to allow for silence after delivering the bad news is integrated into step 4.

Step 5 involves addressing the patient and family's Emotion with Empathy, allowing space for the patient and family to express anger, sadness, disbelief, and so on while validating the emotions and working to align with the patient and family.

The final step, Strategizing and Summarizing, involves exploring what may be most important to the patient in light of the difficult news. This may include things such as symptom relief, allowing family to be present at the time of death, honoring religious and cultural end-of-life traditions. Lastly, the clinician makes a recommendation for a goal-concordant plan and ensures non-abandonment.

A second communication tool is the Serious Illness Conversation Guide (Table 5). Physician and nurse training in conversations about serious illness has increased patient satisfaction about their care (Cohn 2018). Training on use of a Serious Illness Conversation Guide, developed by Ariadne Labs, includes the following components: setting up the conversation, assessing the patient's understanding of their illness, their hopes and worries, sharing prognostic information, exploring what is important to patient and family, and making a recommendation (Ariadne Labs 2017). An aim of this conversation guide is to provide a proven framework for non-palliative care clinicians to more effectively discuss with patients their preferences for end-of-life (Bernacki et al. 2015). This guide can be incorporated into training and utilized by disaster responders.

A third tool comes from the World Health Organization, which developed a guide for field workers on psychological first aid (PFA) (WHO 2018b). This document establishes basic guidelines for talking with colleagues and people of host communities (Table 6). The guide stresses respectful support and emphasizes the importance of being nonintrusive, not pressuring people to talk when they do not want to, and developing a space of safety. It is important to be aware of one's tone of voice, facial expressions, hand gestures, and body language during discussions. The principles of "look, listen, and link" apply to PFA. After establishing that the environment is safe and urgent basic needs of the people have been met, the responder can ask about needs and concerns, give information, listen, and give support. The intervention of providing basic needs is linked to the intervention of psychological first aid and referral for more in-depth counseling.

If possible, it is important to understand how much information to disclose and whom to talk to. Examination of preferences and expectations for medical disclosure of life-limiting diagnoses among patients, families, and community has only occurred in the non-disaster setting. We are unaware of studies reporting on this important issue during disasters and humanitarian crises and must look to the non-disaster literature for cultural guidance. While North American culture expects full disclosure of all medical information, in other cultures, limited information is more acceptable (Walsh et al. 1998; Fujimori and Uchitomi 2009; Orona et al. 1994). Involvement of family members in discussions also varies by culture and country. For instance, in one study, in culturally Japanese patients, $78 \%$ preferred hearing bad news with family members present, compared to $61 \%$ of Portuguese patients and $40 \%$ of Irish patients (Fujimori and Uchitomi 2009). A family-centered approach to communications is dominant in Central and South America (Blackhall et al. 1995). In a study of 150 cancer patients and their relatives and community in Albania, relatives did not want bad news disclosed to the patient (Beqiri et al. 2012). Similarly, a review of 55 publications from the Middle East about disclosure of a cancer diagnosis identified a strong reluctance by family members

Table 6 Psychological first aid

\begin{tabular}{|c|c|}
\hline Approach & Examples \\
\hline Providing practical care and support & "Are you cold? Here is a blanket" \\
\hline Do not supply solutions & $\begin{array}{l}\text { Do not say: "You can have another baby"; do not say: "You're young, } \\
\text { you will marry again" }\end{array}$ \\
\hline Assessing needs and concerns & Need to find family; need for shelter and food \\
\hline Helping people address basic needs & $\begin{array}{l}\text { Identify resources to help deliver food, water, and essential } \\
\text { non-food items }\end{array}$ \\
\hline Listening to people & $\begin{array}{l}\text { "Tell me more ..." } \\
\text { "I hear you saying that ..." }\end{array}$ \\
\hline Comforting people & $\begin{array}{l}\text { "I cannot imagine how difficult this has been." } \\
\text { "I'm so sorry for what you are going through. I'm here to help." }\end{array}$ \\
\hline $\begin{array}{l}\text { Helping people connect to information, } \\
\text { services, and social supports }\end{array}$ & Identifying resources within the community or through aid agencies \\
\hline Protecting people from further harm & Be sensitive that disclosing their experience maybe re-traumatizing \\
\hline
\end{tabular}

(Source: adapted from WHO 2018b) 
and caregivers' attitudes, to allow the patient to know their diagnosis (Khalil 2013).

Host group resilience is related to pre-disaster factors of trust and safety. One study looked at social and occupational factors predicting psychological outcomes among trauma-exposed employees (Brooks et al. 2017). Lower income was associated with post-disaster posttraumatic stress disorder (PTSD). There was no relationship of prior trauma exposure with PTSD from current sudden onset disaster experience. Additionally, social cohesiveness predicts resilience of survivors of disasters (Brockie and Miller 2017). These factors may be important for responders to understand when talking with family members of victims. One report identified that older adults with few social connections were more vulnerable during natural disasters and less likely to be rescued and receive assistance (Dynes 2006). Responders need to be alert to the potential isolation and danger to the surviving elderly spouse of a dying victim.

There are other communication tools for difficult discussions with patients with life-limiting illnesses (Table 7). These tools may be less easily used in the disaster field as they assume an ongoing relationship over time. One of the challenges for responders is the short-term nature of their relationships with victims of disasters. Ideally, the responsibility of difficult conversations rests with a hierarchy of specially trained clinicians who are ideally situated such as psychologists, physicians, and nurses. Additionally, it would be important to train opportunistic individuals such as community representatives or family members in communication skills. In the setting where it is possible to develop long-term infrastructure such as in refugee camps, communication courses and trainings should be offered.

\section{Communication and cultural tools}

Table 8 lists resources and tools to maximize communication and understanding. Physicians who have access to trained interpreters report a significantly higher quality of patient-physician communication than physicians who use other methods, such as untrained staff or family members (Baker et al. 1996). Responders trained in pastoral care and social work can effectively provide emergency palliative care (Rosoff 2010).

When sitting with the dying victim or talking with the bereaved family member, one of the important tasks for responders is to acknowledge the suffering and loss that is going on (Kleinman and Benson 2006). Beyond language and culture, bearing witness for the victim and their family has a healing element. In addition, accompaniment at the end of life is an important aspect of non-abandonment in palliative care and a basic principle of nursing training (Moreno 2019). It is important to express empathy and validate the patient and family reactions and emotions. Always allow the patient to express his fears and concerns. Responders can experience transpersonal experiences with the dying and that these experiences provide comfort to the victims (Broadhurst and Harrington 2016). Transpersonal experiences include a deep sense of identity and empathy with the victim. In addition, there is clear evidence that the long-term outcomes for children exposed to disasters are directly related to parental stress and coping (Pfefferbaum et al. 2015). If responders have on the ground resources such as social workers, early family interventions may reduce long-term PTSD.

Giving bad news is very stressful for the healthcare provider (Ptacek and McIntosh 2009). Whereas in a non-disaster setting, providers can balance bad news with maintaining hope for new treatments and this

Table 7 Tools for communication when long-term follow-up is available

ABCDE (Rabow and McPhee 1999) A: Advance preparation—set a time, invite patient to include a support person, ask what the patient knows.

B: Build a therapeutic environment/relationship—find a private, quiet place, reassure about suffering and non-abandonment.

C: Communicate well-be direct, avoid jargon, allow for silence.

D: Deal with patient and family reactions-listen actively, explore feelings, express empathy.

E: Encourage and validate emotions-correct distortions, assess the effect of the news, address further needs, arrange follow-up.

BREAKS (Narayanan et al. 2010)

B: Background, know the background of the patient/family and understand the clinical problem.

R: Rapport, build rapport, provide time. For discussion

E: Explore, what does the patient know. Include other family or support with patient's permission.

A: Announce, give a warning shot, then deliver the news using straightforward

language.

K: Kindling, address emotions.

S: Summarize, give a summary of the session and set up treatment/care plans.

GUIDE (Back 2013)

G: Get ready — gather data, set up a private and quiet location, ask who needs

to be at the meeting.

$\mathrm{U}$ : Understand-ask the patient what they already know, then listen.

I: Inform—deliver the news in a single sentence, then listen.

D: Deepen - observe and acknowledge emotions; tolerate silence

E: Equip-map out the next steps. Describe treatment options and follow-up. 
Table 8 Resources for communication

\begin{tabular}{|c|c|}
\hline Resources & Examples \\
\hline $\begin{array}{l}\text { Pre-deployment } \\
\text { research }\end{array}$ & $\begin{array}{l}\text { CIA Factbook; Wikipedia, UNHCR, Sphere } \\
\text { Handbook, WHO }\end{array}$ \\
\hline Interpreters & $\begin{array}{l}\text { Team member who are native speakers; } \\
\text { recruit interpreters on the ground }\end{array}$ \\
\hline Cultural guides & $\begin{array}{l}\text { Recruit local leaders who will explain } \\
\text { local customs }\end{array}$ \\
\hline Religious guides & $\begin{array}{l}\text { Understand the local religions } \\
\text { Who are local religious leaders? Imams, } \\
\text { rabbis, priests } \\
\text { Team member who has interfaith } \\
\text { chaplaincy expertize }\end{array}$ \\
\hline $\begin{array}{l}\text { Palliative care } \\
\text { communication } \\
\text { resources }\end{array}$ & $\begin{array}{l}\text { Vital Talk: } \\
\text { https://www.vitaltalk.org/resources/ } \\
\text { (free videos teaching core techniques for } \\
\text { disclosing serious news and other communication } \\
\text { topics) } \\
\text { Ariadne labs: }\end{array}$ \\
\hline & $\begin{array}{l}\text { https://www.ariadnelabs.org/resources/downloads/ } \\
\text { (free download of Serious Illness Conversation Guide) }\end{array}$ \\
\hline
\end{tabular}

strategy can lessen the harshness of the news; this balance is less possible during a disaster (Vogel et al. 2009). Responders who give bad news frequently experience the strong emotions of anxiety, a burden of responsibility for the news, and fear of the recipient's anger or distress (Tesser et al. 1971). Responders also experience their own traumatic stress and compassion fatigue after caring for dying and maimed disaster victims (Lawrence 2017). Additionally, responders can be intensely emotionally connected with deceased victims and feel that they have received communications at the time of the death of the injured. Responders can develop posttraumatic stress disorder (PTSD) from their work after a sudden onset disaster (Sugino et al. 2014). In a crosssectional study of health providers 2 months after the 2015 Nepali earthquake, the prevalence of PTSD was 21.9\% (Shrestha 2015). The level of PTSD in responders can be affected by the amount of social support available (Thormar et al. 2013). It is important to have structured individual and team debriefing for responders after they return from a deployment. After-action debriefing is a standard protocol for disaster teams (FEMA 2019). Experience with debriefing after simulated disasters suggests that further programmatic development is needed to address the emotional stress of a deployment (Greco et al. 2019).

\section{Conclusions and recommendations}

The task of giving bad news is a necessity for physicians of most specialties and is often viewed as challenging and even stressful to some (Ptacek and McIntosh 2009). Communication with victims and their families after a sudden onset disaster adds multiple layers of challenge to care delivery. Many studies have identified the need for disaster management training and palliative care training (Cartwright et al. 2017; Nouvet et al. 2018; Goodman and Black 2018). The new SPHERE handbook and the recent $\mathrm{WHO}$ guidelines on palliative care (WHO et al. 2018) emphasize the importance of integrating physiological, psychological, and spiritual care in all nations and in the setting of humanitarian disasters. The manner in which information is discussed with patients can impact patients' satisfaction, understanding of their illness, and adjustment to the diagnosis, expected quality of life, and intentions to adhere to recommendations (Burgers et al. 2012). Providing bad news in a culturally sensitive manner adds an additional level of complexity to an already challenging encounter. While an individual's culture can strongly influence patient belief systems and utilization of care, there is an inherent danger when responders make assumptions about individuals' culture and the role it plays in their lives.

There are community resources and concrete tools to help responders communicate and comfort devastatingly injured victims. These include local cultural guides, interpreters, and religious leaders. In addition, tools such as the SPIKES sequence for discussing bad news or the Serious Illness Conversation Guide, PFA, compassionate silence and witnessing, and an understanding of transpersonal experiences can comfort victims. There is a need to more critically analyze which of these tools are best suited to a disaster setting. Team organization should include an assigned individual on the team both on the ground and in central command to gather information on the setting: which includes cultural and religious beliefs and basic language phrases. Additionally, the creation and deployment of a Triage and Scarce Resource Allocation Team to oversee and guide ethically challenging clinical decision-making during a crisis period has been proposed as part of tenets and procedures to guide triage assessment and scarce resource allocation during public health emergencies (Kushner et al. 2007). This should be considered as important as the other components such as logistic, operations, and medical surveillance (Powell et al. 2017).

Responders will also be emotionally and psychologically impacted by these experiences. Training must include education about the personal impact of the experience and the importance of the bond of communication between responder and victim. There are measures including training, social support, and attention to safety that can be taken before, during, and after disasters that can reduce stress and increase resilience of responders (Brooks et al. 2016). Overall, there has been a rapid growth of pre-deployment training and professionalization of disaster teams in the past decade (Harvard Humanitarian 
Initiative (HHI) 2018a; Harvard Humanitarian Initiative (HHI) 2018b; Humanitarian 2018). The additional curriculum of communication tools, skills, and attention to the mental and emotional health of responders will be crucial to provide the essential standard of medical care after disasters (The Sphere Handbook 2018; WHO 2012). Palliative care training in general is important in disaster settings to better use limited resources, alleviate suffering of those dying, and through effective communication, improve the resiliency of surviving friends and families.

The next step is to develop a communication guide and field manual for responders and humanitarian workers that focus on communication, delivery of bad news, education and support of host community members in these skills, and protocols for support and stress reduction for disaster responders.

\section{Abbreviations \\ ABCDE: Advance, Build, Communicate, Deal, Encourage; BREAKS: Background, Rapport, Explore, Announce, Kindling, Summarize; $C^{3} D C$ : Cornerstone of cultural competency during the disaster cycle; CAPC: Center to Advance Palliative Care; CIA: Central Intelligence Agency; DHS: Department of Homeland Security; GUIDE: Get ready, Understand, Inform, Deepen, Equip; HHI: Harvard Humanitarian Initiative; HSEEP: Homeland Security Exercise and Evaluation Program; ICRC: International Committee for the Red Cross; LMICs: Low- and middle-income countries; NIH: National Institutes of Health; OSCE: Objective Structured Clinical Examination; PFA: Psychological first aid: PTSD: Posttraumatic stress disorder; SPIKES: Set-up, Perception, Invitation, Knowledge, Emotion and Empathy, Strategy and Summary; UNHCR: United Nations High Commissioner for Refugees; UNISDR: United Nations International Strategy for Disaster Reduction; WHO: World Health Organization}

\section{Acknowledgements}

The authors wish to thank the Massachusetts General Hospital Global Disaster Response for their support of our project.

\section{Funding}

None of the authors received financial support for this article.

\section{Availability of data and materials}

All material and data are referenced from the world's literature.

\section{Authors' contributions}

All authors contributed to the conception, research, and writing of this paper. AG conceived of the study and reviewed the literature. BD designed the tables and analyzed the appropriateness of palliative care tools in the field. AG drafted the paper, while BD, HC, and LB provided contributions within several iterations. All authors read and approved the final manuscript.

\section{Authors' information}

Lynn Black, MD, MPH, is on the faculty of Harvard Medical School and on the clinical staff at Massachusetts General Hospital in the Department of Medicine. She is an Associate in the Center for Global Health and Associate Faculty in the Division of Global Psychiatry. Her positions include Medical Director of MGH Global Disaster Response and the Chief Medical Officer of the Trauma and Critical Care Team for the National Disaster Medical System. She has clinical expertise in emergency medicine, internal medicine, and public health. Her international work has included projects involving access to care, disaster response, refugee health, maternal-child health, and gender-based violence in Africa, Haiti, and Micronesia. Her focus is on the relief of suffering and resilience in both the survivors of disasters and the responders.

Hilarie Cranmer, MD, MPH is an emergency physician and educator working to advance practice standards for humanitarian responders. She responded during the 1999 Kosovo crisis, the 2004 tsunami in Indonesia, the 2005 US hurricanes Katrina and Rita, and the 2010 Haiti earthquake and was the Technical Advisor on Ebola for International Medical Corps during the 2014-2015 Ebola outbreak in West Africa and as Incident Commander for her teams deployed to the Philippines for 2013 Typhoon Haiyan, the 2015 Nepal Earthquake, 2016 Hurricane Matthew-affected Haiti, 2017 Hurricaneaffected Houston, Puerto Rico, and Dominica, and for 2018 Hurricaneaffected North Carolina, Florida, Saipan, and USNS Comfort Operation Enduring Promise for the Venezuelan Migrant crisis. As the founding director of education at the Harvard Humanitarian Initiative, Cranmer designed an innovative training program that culminates in a simulated disaster field experience, now replicated internationally. She is MGH's first director of global disaster response. She was awarded the 2015 Harvard TH Chan School of Public Health Alumni Award of Merit, its highest honor annually bestowed.

Bethany-Rose (BR) Daubman, MD, is an attending physician in the Division of Palliative Care and Geriatrics at Massachusetts General Hospital and an Instructor in Medicine at Harvard Medical School. She is the Assistant Director of Continuing Medical Education and directs several palliative care CME courses through Harvard Medical School. In addition to medical education, she is passionate about international palliative care and has active educational projects around the world including in Jamaica, Kyrgyzstan, and Chile. She worked as the coordinator for the World Health Organization Working Group on Integrating Palliative Care and Symptom Relief into Responses to Humanitarian Emergencies and Crises.

Annekathryn Goodman, MD, MPH, MA, MS is a Professor of Obstetrics, Gynecology and Reproductive Biology at Harvard Medical School and a Fellow of both the American Congress of Obstetricians and Gynecologists and the American College of Surgeons. She has a fulltime practice in Gynecologic Oncology at Massachusetts General Hospital and is an affiliate of MGH Global Disaster Response, the Department of Global Health and Social Medicine at Harvard Medical School, and an Associate of MGH Center for Global Health. In addition to board certification in gynecologic oncology, she is certified in acupuncture and has completed training in both pastoral and palliative care. She is a member of the Ethics Committee at Massachusetts General Hospital. She is a member of the National Trauma and Critical Care Team, a branch of the US Department of Health and Human Services, and has deployed to various international disasters. Since 2008 , she has been consulting in Bangladesh on cervical cancer prevention and the development of medical infrastructure to care for women with gynecologic cancers.

\section{Competing interests}

The authors declare that they have no competing interests.

\section{Publisher's Note}

Springer Nature remains neutral with regard to jurisdictional claims in published maps and institutional affiliations.

\section{Author details \\ 'Division of Palliative Care and Geriatrics, Massachusetts General Hospital, Boston, MA, USA. ${ }^{2}$ MGH Global Health, Department of Emergency Medicine, Massachusetts General Hospital, Boston, USA. ${ }^{3}$ MGH Global Health, Department of Medicine, Massachusetts General Hospital, Boston, USA. ${ }^{4}$ MGH Global Health, Department of Obstetrics and Gynecology, Massachusetts General Hospital, Boston, USA.}

Received: 25 February 2019 Accepted: 8 May 2019

Published online: 22 May 2019

\section{References}

Abubakar I, Aldridge RW, Devakumar D, Orcutt M, Burns R, Barreto ML, Dhavan P, Fouad FM, Groce N, Guo Y, Hargreaves S, Knipper M, Miranda JJ, Madise N, Kumar B, Mosca D, McGovern T, Rubenstein L, Sammonds P, Sawyer SM, Sheikh K, Tollman S, Spiegel P, Zimmerman C, on behalf of the UCL-Lancet Commission on Migration and Health (2019) The UCL-Lancet Commission on Migration and Health: the health of a world on the move. Lancet 392(10164): 2606-2654

Alpert EA, Jaffe E (2018) EMS, catastrophic events. StatPearls Treasure Island (FL): StatPearls Publishing https://www.ncbi.nlm.nih.gov/books/NBK532920/ Accessed 12 Feb 2019 
Ariadne Labs (2017) Serious illness conversation guide. https://www.ariadnelabs. org/wp-content/uploads/sites/2/2018/04/Serious-IIness-Conversation-Guide 2017-04-18CC2pg.pdf. Accessed 17 Jan 2019

Asgary R, Jacobsen K (2013) Comprehensive on-site medical and public health training for local practitioners in a refugee setting. Disaster Med Public Health Prep 7(1):82-88

Back AL. (2013) Vital Talk (1.0) [Mobile application software] Retrieved from http:// vitaltalk.org. Accessed 16 Feb 2019

Baile WF, Buckman R, Lenzi R, Glober G, Beale EA, Kudelka AP (2000) SPIKES—a six-step protocol for delivering bad news: application to the patient with cancer. Oncologist 5(4):302-311

Baker DW, Parker RM, Williams MV, Coates WC, Pitkin K (1996) Use and effectiveness of interpreters in an emergency department. JAMA 275(10): 783-788

Barclay JS, Blackhall LJ, Tulsky JA (2007) Communication strategies and cultural issues in the delivery of bad news. J Palliative Med 10(4):958-977

Barilan YM, Brusa M, Halperin P (2014) Triage in disaster medicine: ethical strategies in various scenarios. In: Disaster bioethics: normative issues when nothing is normal. Public health ethics analysis. Springer, Dordrecht, pp 49-63

Beqiri A, Toci E, Sallaku A, Qirjako G, Burazeri G (2012) Breaking bad news in a southeast European population: a survey among cancer patients in Albania. J Palliat Med 15(10):1100-1105

Bernacki R, Hutchings M, Vick J, Smith G, Paladino J, Lipsitz S, Gawande AA, Block SD (2015) Development of the Serious IIIness Care Program: a randomised controlled trial of a palliative care communication intervention. BMJ Open 5(10):e009032. https://doi.org/10.1136/bmjopen-2015-009032

Betancourt JR, Green AR, Carrillo JE, Ananeh-Firempong O (2003) Defining cultural competence: a practical framework for addressing racial/ethnic disparities in health and health care. Pub Health Rep 118(4):293-302

Biddison LD, Berkowitz KA, Courtney B, De Jong CM, Devereaux AV, Kissoon N, Roxland BE, Sprung CL, Dichter JR, Christian MD, Powell T, Task Force for Mass Critical Care (2014) Ethical considerations: care of the critically ill and injured during pandemics and disasters: CHEST consensus statement. Chest 146(4 suppl):e145S-e155S

Binder SB, Baker CK (2017) Culture, local capacity, and outside aid: a community perspective on disaster response after the 2009 tsunami in American Sāmoa. Disasters. 41(2):282-305

Blackhall LJ, Murphy ST, Frank G, Michel V, Azen S (1995) Ethnicity and attitudes toward patient autonomy. JAMA 274(10):820-825

Bogucki S, Jubanyik K (2009) Triage, rationing, and palliative care in disaster planning. Biosecur Bioterror 7(2):221-224

Brezis M, Lahat Y, Frankel M, Rubinov A, Bohm D, Cohen MJ, Koslowsky M, Shalomson O, Sprung CL, Perry-Mezare H, Yahalom R, Ziv A (2017) What can we learn from simulation-based training to improve skills for end-of-life care? Insights from a national project in Israel. Israel J Health Policy Res 6(1):48. https://doi.org/10.1186/s13584-017-0169-9 https:// www.ncbi.nlm.nih.gov/pmc/articles/PMC5674237/

Broadhurst K, Harrington A (2016) A thematic literature review: the importance of providing spiritual care for end-of-life patients who have experienced transcendence phenomena. Am J Hosp Palliat Care 33(9):881-893

Brockie L, Miller E (2017) Understanding older adults' resilience during the Brisbane floods: social capital, life experience, and optimism. Disaster Med Public Health Prep 11(1):72-79

Brooks SK, Dunn R, Amlôt R, Greenberg N, Rubin GJ (2016) Social and occupational factors associated with psychological distress and disorder among disaster responders: a systematic review. BMC Psychol 4:18. https://doi.org/10.1186/s40359-016-0120-9

Brooks SK, Dunn R, Amlôt R, Rubin GJ, Greenberg N (2017) Social and occupational factors associated with psychological wellbeing among occupational groups affected by disaster: a systematic review. J Ment Health 26(4):373-384

Burgers C, Beukeboom CJ, Sparks L (2012) How the doc should (not) talk: when breaking bad news with negations influences patients' immediate responses and medical adherence intentions. Patient Educ Couns 89(2): 267-273

Burkle FM (2018) Triage and the lost art of decoding vital signs: restoring physiologically based triage skills in complex humanitarian emergencies. Disaster Med Public Health Prep 12(1):76-85

CAPC Center to Advance Palliative Care (2019) "About palliative care." (https:// www.capc.org/about/palliative-care/. Accessed 12 Feb 2019
Caro JJ, DeRenzo EG, Coleman NC, Weinstock DM, Knebel AR (2011) Triage and treatment tools for use in a scarce resources-crisis standards of care setting after a nuclear detonation. Disaster Med Public Health Prep 5(suppl(1):546-553

Cartwright C, Hall M, Lee ACK (2017) The changing health priorities of earthquake response and implications for preparedness: a scoping review. Public Health 150:60-70. https://doi.org/10.1016/j.puhe.2017.04.024

Cherny NI (2007) Palliative care in situations of conflict: lessons from Jerusalem. Am J Hosp Palliative Care 23(6):469-474

Cohn J (2018) Advanced serious illness, multimorbidity, and multibeneficence: the role of communication. J Eval Clin Pract 24(6):1279-1281

Danna DM, Pierce SS, Schaubhut RM, Billingsley L, Bennett MJ (2015) Educating nurses to provide culturally competent care during disasters. J Contin Educ Nurs 46(3):135-144

De Jong MJ, Benner R, Benner P, Richard ML, Kenny DJ, Kelley P, Bingham M, Debisette AT (2010) Mass casualty care in an expeditionary environment: developing local knowledge and expertise in context. J Trauma Nurs 17(1):45-58

Dhillon P. McCarthy S, Gibbs M, Sue K (2015) Palliative care condundrums in an Ebola treatment centre. BMJ Case Rep 2015:bcr2015211384. https://doi.org/ $10.1136 / \mathrm{bcr}-2015-211384$

DHS. The U.S. Department of Homeland Security (2013) Homeland Security Exercise and Evaluation Program (HSEEP). DHS, Washington D.C https:// www.fema.gov/media-library/assets/documents/32326. Accessed 16 Feb 2019

Downar J, Seccareccia D, Associated Medical Services Inc. Educational Fellows in care at the End of Life (2010) Palliating a pandemic. "All patients must be cared for". J Pain Symptom Manag 39(2):291-295

Dudley MHG (2013) Mass fatality management concise field guide. First edition CRC Press Taylor \& Francis Group, Baco Raton London New York

Dunin-Bell O (2018) What do they know? Guidelines and knowledge translation for foreign health sector workers following natural disasters. Prehosp Disaster Med 33(2):139-146

Dynes R (2006) Social capital: dealing with community emergencies. Homeland Security Affairs 2(2):1-26

Fallowfield L, Jenkins V (2004) Communicating sad, bad, and difficult news in medicine. Lancet 363(9405):312-319

FEMA (2019) After-action report. https://www.fema.gov/pdf/emergency/usr/ usr006.pdf. Accessed 14 Apr 2019

Fowler-Kerry S, Cunningham C (2010) Thinking about the effects of a natural disaster of existing palliative care needs. Int J Palliat Nurs 16(5):255

Fujimori M, Uchitomi Y (2009) Preferences of cancer patients regarding communication of bad news: a systematic literature review. Jpn J Clin Oncol 39(4):201-216

Goodman A, Black L (2015) The challenge of allocating scarce medical resources during a disaster in a low-income country: a case study from the 2010 Haitian earthquake. Palliat Med Hosp Care - Open J 1(1):24-29

Goodman A, Black L (2018) Palliative care training for work in an austere environment after a natural disaster. Palliat Med Hosp Care Open J 4(1):1013. https://doi.org/10.17140/PMHCOJ-4-12 https://openventio.org/wpcontent/uploads/Palliative-Care-Training-for-Work-in-an-Austere-Environmentafter-a-Natural-Disaster-PMHCOJ-4-128.pdf. Accessed 13 Feb 2019

Greco S, Lewis EJ, Sanford J, Sawin EM, Ames A (2019) Ethical reasoning debriefing in disaster simulations. J Prof Nurs 35(2):124-132

Greisinger AJ, Lorimor RJ, Aday LA, Winn RJ, Baile WF (1997) Terminally ill cancer patients: their most important concerns. Cancer Pract 5(3):147-154

Grock A, Aluisio AR, Abram E, Roblin P, Arquilla B (2017) Evaluation of the association between disaster training and confidence in disaster response among graduate medical trainees: a cross-sectional study. Am J Disaster Med 12(1):5-9. https://doi.org/10.5055/ajdm.2017.0253

Harvard Humanitarian Initiative (HHI). (2018a) Disasternet. https://hhi.harvard.edu/ research/disasternet. Accessed 16 Feb 2019

Harvard Humanitarian Initiative (HHI). (2018b) Disasters and emergencies preparedness programme. https://hhiharvardedu/content/disasters-andemergencies-preparedness-programme Accessed 16 Feb 2019

Humanitarian U (2018) DisasterReady. https://humanitarianu.com/ Accessed 16 Feb 2019

IFRC (2014) Chapter 6: Culturally sensitive public health: the HIV/AIDS disaster and beyond. https://www.ifrc.org/publications-and-reports/world-disastersreport/world-disasters-report-2014/world-disasters-report-2014--chapter-6/. Accessed 16 Feb 2019 
Jacobsen J, Alexander Cole C, Daubman BR, Banerji D, Greer JA, O'Brien K, Doyle K, Jackson VA (2017) A novel use of peer coaching to teach primary palliative care skills: coaching consultation. J Pain Symptom Manag 54(4):578-582

Kelman I (2012) Disaster diplomacy: how disasters affect peace and conflict, 1st edn. Routledge Taylor \& Francis Group, London and New York

Khalil RB (2013) Attitudes, beliefs and perceptions regarding truth disclosure of cancer-related information in the Middle East: a review. Palliat Supp Care 11(1):69-78

Kleinman A, Benson P (2006) Anthropology in the clinic: the problem of cultural competency and how to fix it. PLoS Med 3(10):e294

Kushner WG, Pollard JB, Ezeji-Okoye SC (2007) Ethical triage and scarce resource allocation during public health emergencies: tenets and procedures. Hosp Top 85(3):16-25

Lamba S, Tyrie LS, Bryczkowski S, Nagurka R (2016) Teaching surgery residents the skills to communicate difficult news to patient and family members: a literature review. J Palliat Med 19(1):101-107

Lavizzo-Mourey RJ, MacKenzie E (1996) Cultural competence--an essential hybrid for delivering high quality care in the 1990's and beyond. Trans Am Clin Climatol Assoc 107:226-235; discussion 236-237

Lawrence M (2017) Near-death and other transpersonal experiences occurring during catastrophic events. Am J Hosp Palliat Care 34(5):486-492

Lempert KD, Kopp JB (2013) Hurricane Sandy as a kidney failure disaster. Am J Kidney Dis 61(6):865-658

Marston J, Lima LD, Powell RA, Palliative Care in Complex Humanitarian Emergencies Network (2015) Palliative care in complex humanitarian crisis responses. Lancet 386(10007):1940. https://doi.org/10.1016/S01406736(15)00825-9

Matzo M, Wilkinson A, Lynn J, Gatto M, Phillips S (2009) Palliative care considerations in mass casualty events with scarce resources. Biosecur Bioterror 7(2):199-210

Maynard DW (1996) On "realization" in everyday life: the forecasting of bad news as a social relation. Am Sociol Rev 61(1):109-131

Monden KR, Gentry L, Cox TR (2016) Delivering bad news to patients. Proc (Baylor Univ Med Cent) 29(1):101-102

Moreno IM (2019) Returning to the accompaniment at the end of life as an important nursing care in palliative care. Hosp Palliat Care Int J 3(1):1-2

Morgan Banks L, Kuper H, Polack S (2017) Poverty and disability in low- and middle-income countries: a systematic review. PLoS One 12(12):e0189996

Narayanan V, Bista B, Koshy C (2010) "BREAKS" protocol for breaking bad news. Indian J Palliat Care 16(2):61-65

National Institutes of Health (NIH). (2017) Cultural competence - clear communication. https://www.nih.gov/institutes-nih/nih-office-director/officecommunications-public-liaison/clear-communication Accessed 16 Feb 2019

Nouvet E, Sivaram M, Bezanson K, Krishnaraj G, Hunt M, de Laat S, Sanger S, Banfiled L, Rodriguez PFE, Schwartz $\sqcup$ (2018) Palliative care in humanitarian crises: a review of the literature. J Int Humanitarian Action 3:5. https://doi. org/10.1186/s41018-018-0033-8

Orona CJ, Koenig BA, Davis AJ (1994) Cultural aspects of nondisclosure. Camb Q Health Ethics 3(3):338-346

Pfefferbaum B, Jacobs AK, Houston JB, Griffin N (2015) Children's disaster reactions: the influence of family and social factors. Curr Psychiatry Rep 17(7):57

Powell RA, Schwartz L, Nouvet E, Sutton B, Petrova M, Marston J, Munday D, Radbruch $L$ (2017) Palliative care in humanitarian crises: always something to offer. Lancet 389(10078):1498-1499

Powell T (2010) Family participation in the care of patients in public health disasters. J Clin Ethics 21(4):288-293

Ptacek JT, Mclntosh EG (2009) Physician challenges in communicating bad news. J Behav Med 32(4):380-387

Rabow MW, McPhee SJ (1999) Beyond breaking bad news: how to help patients who suffer. West J Med 171(4):260-263

Rollins LK, Hauck FR (2015) Delivering bad news in the context of culture: a patient centered approach. J Clin Outcomes Manag 22(1) https://www. mdedge.com/jcomjournal/article/146721/practice-management/deliveringbad-news-context-culture-patient-centered. Accessed 16 Feb 2019

Rosoff PM (2010) Should palliative care be a necessity or a luxury during an overwhelming health catastrophe? J Clin Ethics 21(4):288-293

Sabri AA, Qayyum MA (2006) Why medical students should be trained in disaster management: our experience of the Kashmir earthquake. PLoS Med 3(9): $1452-1453$
Shrestha R (2015) Post-traumatic stress disorder among medical personnel after Nepal earthquake, 2015. J Nepal Health Res Counc 13(30):144-148

Smith J, Aloudat T (2017) Palliative care in humanitarian medicine. Palliat Med 31(2):99-101

Smith RM, Dyer GSM, Antonangeli K, Arredondo N, Bedlion H, Dalal A, Deveny GM, Joseph G, Lauria D, Lockhart SH, Lucien S, Marsh S, Rogers SO, Salzarulo H, Shah S, Toussaint RJ, Wagoner J (2012) Disaster triage after the Haitian earthquake. Injury 43(11):1811-1815

Smith SM, Gorski J, Vennelakanti HC (2010) Disaster preparedness and response: a challenge for hospitals in earthquake-prone countries. Int J Emerg Manag 7(3/4):209-220

Sugino M, Hapsari ED, Madyaningrum E, Haryant F, Warsini S, Takada S, Matsuo H (2014) Issues raised by nurses and midwives in a post-disaster Bantul community. Disaster Prev Manag 23(4):420-436

Tesser A, Rosen S, Tesser M (1971) On the reluctance to communicate undesirable messages (the MUM effect). A field study. Psychol Rep 29(2):651-654

The Sphere Handbook (2018) https://spherestandards.org/wp-content/uploads/ Sphere-Handbook-2018-EN.pdf. Accessed 13 Feb 2019

Thormar SB, Gersons BPR, Juen B, Djakababa MN, Karlsson T, Olff M (2013) Organizational factors and mental health in community volunteers. The role of exposure, preparation, training, tasks assigned, and support. Anxiety Stress Coping 26(6):624-642

UNHCR (2018) Global trends: forced displacement in 2017. United Nations High Commissioner for Refugees, Geneva https://www.unhcr.org/5b27be547.pdf, Accessed 01 Feb 2019

UNHCR (2019) Shelter solutions. UNHCR the UN refugee agency emergency handbook. https://emergency.unhcr.org/entry/254351/shelter-solutions

UNISDR (2015) Making development sustainable: the future of disaster risk management. Global assessment report on disaster risk reduction. United Nations Office for Disaster Risk Reduction (UNISDR), Geneva Available from: http://www.preventionweb.net/english/hyogo/gar/2015/en/gar-pdf/ GAR2015 EN.pdf. Accessed 13 Feb 2019

Vail L, Sandhu H, Fisher J, Cooke H, Dale J, Barnett M (2011) Hospital consultants breaking bad news with simulated patients: an analysis of communication using the Roter Interaction Analysis System. Patient Educ Couns 83(2):185-194

Vogel BA, Leonhart R, Helmes AW (2009) Communication matters: the impact of communication and participation in decision making on breast cancer patients' depression and quality of life. Patient Educ Couns 77(3):391-397

Walsh RA, Girgis A, Sanson-Fisher RW (1998) Breaking bad news 2: what evidence is available to guide clinicians. Behav Med 24(2):61-73

WHO (2012) World Health Organization. Toolkit for assessing health-system capacity for crisis management. http://www.euro.who.int/__data/assets/pdf_ file/0008/157886/e96187.pdf. Accessed 16 Feb 2019

WHO (2018a). World Health Organization. Emergency and essential surgical care: disasters and emergencies. http://www.who.int/surgery/challenges/esc_ disasters emergencies/en/ Accessed 13 Feb 2019

WHO (2018b). World Health Organization. Psychological first aid: guide for field workers. https://www.who.int/mental_health/publications/guide_field_ workers/en/ Accessed 16 Feb 2019

WHO; Aloudat, T, Berterame, S, Bhadelia, N, Daubman, B-R, Goodman, A, Janjanin, S, Krakauer, E, Ntizimira, C, Schwartz, L, Sutton, B, Weissbecker, I. (2018). Integrating palliative care and symptom relief into the response to humanitarian emergencies and crises: a WHO guide. Licence: CC BY-NC-SA 3. 0 IGO. https://apps.who.int/iris/bitstream/handle/10665/274565/ 9789241514460-eng.pdf?ua=1. Accessed 12 Feb 2019

WHO/ICRC. (2017). Technical meeting for global consensus on triage 2017 https://www.humanitarianresponse.info/sites/www.humanitarianresponse. info/files/documents/files/triage_2017_meeting_report-b.pdf. Accessed 6 Feb 2019

Wilkinson A (2012) The potential role for palliative care in mass casualty events. J Palliat Care Med 2:e112. https://doi.org/10.4172/2165-7386.1000e112

Zhao L, Li H, Sun Y, Huang R, Hu O, Wang J, Gao F (2017) Planning emergency shelters for urban disaster resilience: an integrated location-allocation modeling approach. Sustainability 9(11):2098. https://doi.org/10.3390/ su9112098 